\title{
Reduced bacterial growth and increased osteoblast proliferation on titanium with a nanophase $\mathrm{TiO}_{2}$ surface treatment
}

This article was published in the following Dove Press journal:

International Journal of Nanomedicine

6 January 2017

Number of times this article has been viewed

\section{Garima Bhardwaj \\ Thomas J Webster}

Department of Chemical Engineering, Northeastern University, Boston, MA, USA
Correspondence: Thomas J Webster

313 Snell Engineering Center

Northeastern University

Boston, MA 02115, USA

Email bhardwaj.g@husky.neu.edu
Background: The attachment and initial growth of bacteria on an implant surface dictates the progression of infection. Treatment often requires aggressive antibiotic use, which does not always work. To overcome the difficulties faced in systemic and local antibiotic delivery, scientists have forayed into using alternative techniques, which includes implant surface modifications that prevent initial bacterial adhesion, foreign body formation, and may offer a controlled inflammatory response.

Objective: The current study focused on using electrophoretic deposition to treat titanium with a nanophase titanium dioxide surface texture to reduce bacterial adhesion and growth. Two distinct nanotopographies were analyzed, Ti-160, an antimicrobial surface designed to greatly reduce bacterial colonization, and Ti-120, an antimicrobial surface with a topography that upregulates osteoblast activity while reducing bacterial colonization; the number following $\mathrm{Ti}$ in the nomenclature represents the atomic force microscopy root-mean-square roughness value in nanometers.

Results: There was a 95.6\% reduction in Staphylococcus aureus (gram-positive bacteria) for the Ti-160-treated surfaces compared to the untreated titanium alloy controls. There was a $90.2 \%$ reduction in Pseudomonas aeruginosa (gram-negative bacteria) on Ti-160-treated surfaces compared to controls. For ampicillin-resistant Escherichia coli, there was an $81.1 \%$ reduction on the Ti-160-treated surfaces compared to controls. Similarly for surfaces treated with Ti-120, there was an $86.8 \%$ reduction in $S$. aureus, an $82.1 \%$ reduction in $P$. aeruginosa, and a $48.6 \%$ reduction in ampicillin-resistant $E$. coli. The Ti-120 also displayed a $120.7 \%$ increase at day 3 and a $168.7 \%$ increase at day 5 of osteoblast proliferation over standard titanium alloy control surfaces.

Conclusion: Compared to untreated surfaces, Ti-160-treated titanium surfaces demonstrated a statistically significant $1 \log$ reduction in $S$. aureus and $P$. aeruginosa, whereas Ti-120 provided an additional increase in osteoblast proliferation for up to 5 days, criteria, which should be further studied for a wide range of orthopedic applications.

Keywords: nanotopography, infection, titanium dioxide, electrophoretic deposition

\section{Introduction}

Millions of medical devices are used each year, and despite many advances in biomaterials, a proportion of each type of device becomes colonized by bacteria. ${ }^{1}$ Implanted devices may be colonized by bacteria at the time of surgery or via a hematogenous route from a distant source. The most significant factor in the development of device-related infections appears to be the skill of the surgical team; prosthetic hips have been reported to become infected in $<0.2 \%$ of cases, but in as many as $4 \%$ of cases in less proficient facilities. Generally, large and complex medical devices that 
require long and complicated surgery for their placement are at high risk of bacterial infection. ${ }^{2}$ When infection occurs, it can be life threatening. Device-related infections may occur almost immediately postsurgery or may be very slow to develop, with overt symptoms occurring months, or even years, after the device is implanted.

Most medical device infections are currently treated by the use of antibiotics. This strategy targets free-floating planktonic bacteria and fails to target the biofilm-forming bacteria that are more sessile. The threat of antibiotic resistance is also real because of the increasing occurrence of antibiotic-resistant strains of bacteria, especially multi drug resistant Staphylococcus aureus (MRSA).

Nanotechnology is a promising alternative to overcome the problems faced in the traditional administration of proteins, peptides, and new drugs found in the discovery pipeline. Many of these drugs that are used to fight infections have been shown to be poorly soluble in aqueous and organic media and show erratic absorption and poor bioavailability. Nanoparticles can be used to increase efficacy and decrease toxicity by controlling biodistribution, improving intracellular penetration, facilitating absorption through the mucosa, and improving protection against degradation. Implant materials that prevent initial bacterial adhesion are an important tool for fighting infections. ${ }^{3}$ Bacterial growth and adhesion can be controlled by altering various surface properties such as porosity, roughness, hydrophobicity, hydrophilicity, the use of a functional group, etc. The biocompatibility of titanium is closely related to the properties of the surface oxide layer in terms of its structure, morphology, and composition. ${ }^{4}$ The titanium oxide is a naturally occurring surface property of titanium. Various physical and chemical treatments of the Ti surface have been proposed with the aim of enhancing osseointegration and improving initial stability. The approaches that have been found to be beneficial to the biological performance of the implants include increasing the surface roughness and oxidation to form thicker or otherwise modified titanium dioxide $\left(\mathrm{TiO}_{2}\right)$ layers on the surface. ${ }^{5}$ Several antibiotics (such as vancomycin) have been incorporated into coatings on Ti surfaces, but issues of optimal incorporation and controlled release have yet to be dealt with. ${ }^{6}$ One major restriction on the incorporation of antibiotics in coatings is the use of high temperature processes such as plasma spraying that denatures the coating. ${ }^{7-9}$ Furthermore, the loading capacity and the release kinetics of antibiotics are restricted by their physical adsorption onto substrates and their use could trigger antibiotic resistance, which is a problem yet to be solved..$^{10,11}$
Coatings that reduce bacterial attachment are possible by modifying the implant surface to have structures that alter the surface energy and also provide mechanical cues that disrupt the bacterial membrane. ${ }^{12}$ Many studies have indicated that surface roughness and hydrophobicity are primarily responsible for controlling bacterial attachment, and since nanostructures give us the ability to do so, nanostructured implant surfaces are far better for reducing orthopedic infections than conventionally structured implants. Thus, by incorporating nanofeatures onto implant surfaces, the orthopedic infections can be reduced by up to five times as compared to plasma-sprayed implants, which create conventional, micron-structured features. ${ }^{13-15}$

There are three primary crystalline phases of $\mathrm{TiO}_{2}$ (anatase, rutile, and brookite) with different sizes of crystal cells in each case. ${ }^{1}$ The photolytic abilities of $\mathrm{TiO}_{2}$ have been utilized widely for the preparation of different types of nanomaterials, including nanoparticles, nanorods, nanowires, nanotubes, and mesoporous and nanoporous materials. ${ }^{2}$ The photolytic abilities of Ti are maintained regardless of the scale. In addition, nanoscale $\mathrm{TiO}_{2}$ has a surface reactivity that fosters interactions with biological molecules, such as phosphorylated proteins and peptides, ${ }^{3}$ as well as some nonspecific binding with DNA. ${ }^{4}$

Compared to other advanced shaping techniques, electrophoretic deposition (EPD) is a very versatile plasma-based coating process since it can be modified easily for a specific application. For example, the titanium oxide texturing can be made on flat, cylindrical, or any other shaped substrate with only minor changes in electrode design and positioning. In particular, despite being a wet process, EPD offers easy control over the thickness and morphology of the surface topography through the simple adjustment of the coating time, solution $\mathrm{pH}$, and applied potential. ${ }^{16}$ The following study used EPD to treat Ti-6Al-4V to modify the surface of $\mathrm{TiO}_{2}$ to create a nanotopography to prevent bacterial adhesion and proliferation while either maintaining or accelerating osteoblast growth.

\section{Materials and methods Nanotreatment - electrophoretic processing, EPD}

Using ethanol as the electrophoretic medium, the EPD cell was established using titanium as the anode and the titanium sample as the cathode. A potential difference of $40-80 \mathrm{~V}$ for a minute per sample was used to obtain a uniform topography. The treated samples (the surface modified titanium samples) were dried overnight and sintered in a furnace to finish the 
process. The processing parameters were adjusted to produce the two distinct surface nanotopographies for Ti-120 and Ti-160.

\section{Surface characterization}

After the nanotreatment, the samples were characterized under scanning electron microscopy to visualize the nanoscale topography. ${ }^{17}$ The nanosurfaces were also characterized by atomic force microscopy (AFM) to provide scale and quantitative topography measurements. Following material characterization, the samples were cleaned by washing with $70 \%$ ethanol for 5 minutes and then were sterilized under ultraviolet light overnight. They were washed thrice with phosphate-buffered saline (PBS) prior to seeding the cells on the surface.

\section{Bacterial assays}

Bacterial assays were conducted using the following three strains of bacteria: Staphylococcus aureus $\left(\mathrm{ATCC}^{\circledR} 29740^{\mathrm{TM}}\right.$ ), Pseudomonas aeruginosa $\left(\mathrm{ATCC}^{\circledR} 39324^{\mathrm{TM}}\right.$ ), and an ampicillin-resistant strain of Escherichia coli (Bio-Rad Strain HB101 K-12 \# 166-0408 and pGLO Plasmid \# 166-0405). Agar (Sigma-Aldrich, cat \# A1296) and 0.03\% tryptic soy broth (TSB; Sigma-Aldrich, St Louis, MO, USA; cat \# 22092) were used as the media. A single colony from the inoculation plate was used for each experiment. A small amount of bacteria was taken from the stock culture, streaked onto an agar plate, and then used as the stock plate for further experiments. One colony from the TSB agar plate was added to $5 \mathrm{~mL}$ of $3 \%$ TSB and incubated at $37^{\circ} \mathrm{C}$ in humidified conditions under a $5 \%$ carbon dioxide atmosphere for 16 hours. A total of $10^{6} \mathrm{cells} / \mathrm{mL}$ were seeded onto the material surface and incubated for 16 hours at $37^{\circ} \mathrm{C}$. The supernatant was removed, and the samples were rinsed twice with PBS followed by sonication for 5 minutes in PBS. The supernantant was once more switched with fresh PBS, and the samples were sonicated for an additional 10 minutes. The final bacterial suspension was diluted to create subsequent dilutions $\left(10^{-3}\right.$ and $\left.10^{-4}\right)$. Following this, $0.1 \mathrm{~mL}$ of each of the $10^{-3}$ and $10^{-4}$ dilutions was plated and incubated for 16 hours. The number of bacterial colonies formed on each sample was counted, and using these values, the number of bacteria per milliliter was determined.

\section{Cell culture}

Osteoblasts from ATCC (cat\#C12720, population numbers 1-3; American Type Culture Collection, Manassas, VA, USA) were grown in Dulbecco's Modified Eagle's Medium supplemented with $10 \%$ fetal bovine serum and $1 \%$ penicillin (HyClone; Thermo Fisher Scientific, Waltham, MA, USA).
The samples were sterilized with $70 \%$ ethanol for 20 minutes and then rinsed thrice with PBS. An 3-(4,5-dimethylthiazol2-yl)-5-(3-carboxymethoxyphenyl)-2-(4-sulfophenyl)2H-tetrazolium, inner salt (MTS) assay was used to determine cell adhesion and proliferation after 1,3, and 5 days. The cells were seeded at 5,000 cells $/ \mathrm{cm}^{2}$ for the adhesion and proliferation assays, and the media were changed every other day. The MTS (CellTiter $96^{\circledR} \mathrm{AQ}_{\text {ueous }}$ One Solution Cell Proliferation Assay, G3581 Promega) reagent (1:5 ratio with cell culture media) was added to each well and incubated for 3 hours on the day of the measurement. Absorbance from each well was measured by a SpectraMax M3 (MT05412) at $490 \mathrm{~nm}$, and a color change from pink to dark brown was seen.

\section{Statistical analysis}

Each experiment was completed in triplicate with new bacteria, osteoblasts, media, and samples. A $P$-value of $<0.01$ was deemed to be statistically significant.

\section{Results \\ Surface characterization}

The surface of the EPD-coated samples showed enhanced nanoscale features as depicted in Figure 1, which is a scanning electron microscopic image of the Ti-120- and Ti-160-treated and -untreated samples. The number following $\mathrm{Ti}$ in the nomenclature represents the AFM root-mean-square (RMS) roughness value in nanometers. The untreated Ti alloy control was much smoother at the nanoscale, possessing RMS values of $40 \mathrm{~nm}$ for this $2 \times 2 \mu \mathrm{m}$ AFM scan.

\section{Bacterial adhesion and growth}

The bacterial assays conducted demonstrated that there was a significant decrease in bacterial adhesion across all three strains of bacteria on the nanotextured Ti. There was a $95.6 \%$ decrease (a $1 \log$ reduction) for $S$. aureus, a $90.2 \%$ decrease (a $1 \log$ reduction) for $P$. aeruginosa, and an $81.1 \%$ decrease (close to a $1 \log$ reduction) for ampicillin-resistant E. coli for the Ti-160 surfaces. For Ti-120, there was an $86.8 \%$ reduction in S. aureus, an $82.1 \%$ reduction in $P$. aeruginosa, and a $48.6 \%$ reduction in ampicillin-resistant $E$. coli. The graphical results are depicted in Figures 2-4. Graphs were plotted to show the number of bacteria versus the RMS roughness of the treated and control samples, and it was seen that there was an almost linear relationship with $R^{2}$ values of $0.93855,0.93797$, and 0.99574 for $S$. aureus, $P$. aeruginosa, and ampicillin-resistant E. coli, respectively (Figure 5). This demonstrates that the nanoscale roughness created was the primary factor, resulting in a decrease in bacteria density on the nanotextured samples. 

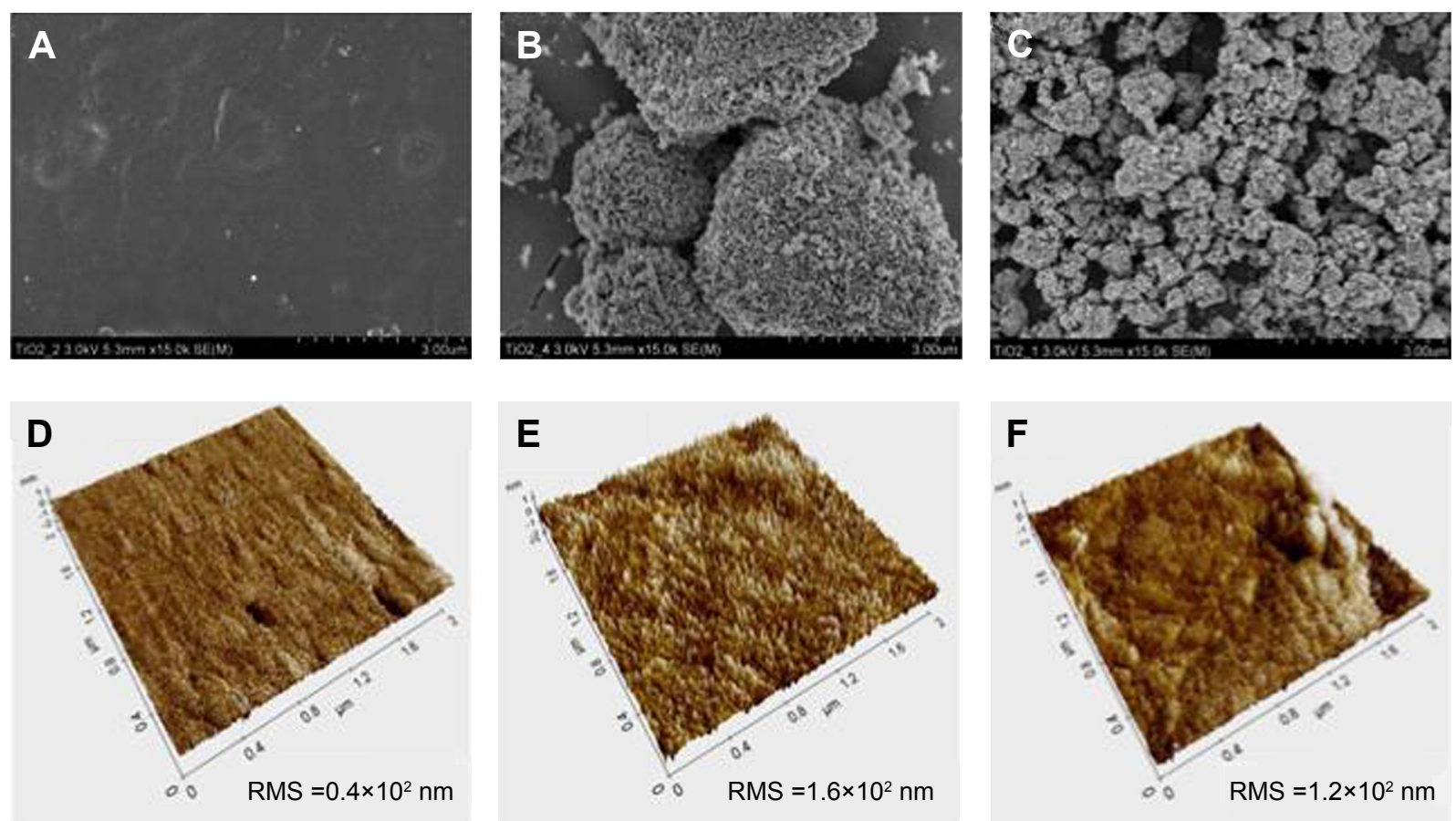

Figure I SEM images of the (A) untreated titanium, (B) Ti-I20, and (C) Ti- I60 as well as AFM of (D) untreated titanium, (E) Ti- I20, and (F) Ti- I60 illustrating the nanoscale surface topography.

Abbreviations: SEM, scanning electron microscopic; AFM, atomic force microscopy; RMS, root-mean-square.

\section{Osteoblast proliferation}

Figure 6 illustrates the improved osteoblast proliferation achieved on the samples treated with Ti-120 versus untreated Ti. Combined with the results mentioned earlier, the results indicated that the Ti-120 surface topography led to decreased bacterial colonization with increased osteoblast proliferation. Importantly, such results were achieved by only changing the raw surface roughness values at the nanoscale and not using antibiotics or growth factors.

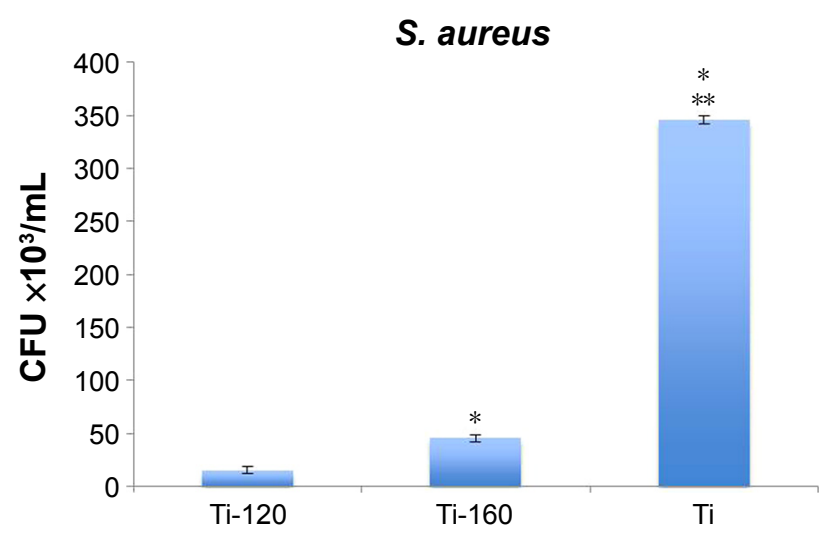

Figure 2 S. aureus colony-forming units per milliliter on plain titanium and treated titanium.

Notes: Data are expressed as the mean \pm standard error of the mean; $N=3$; $* \mathrm{P}<0.0 \mathrm{I}$ compared with $\mathrm{Ti}-\mathrm{I} 20$ and $* * \mathrm{P}<0.0 \mathrm{I}$ compared with $\mathrm{Ti}-\mathrm{I} 20$ and $\mathrm{Ti}-\mathrm{I} 60$.

Abbreviation: S. aureus, Staphylococcus aureus.

\section{Discussion}

Since the natural hierarchy of the body shows that most interactions take place at the nanoscale, the effect of nanotopographical cues on cell adhesion and proliferation, inflammation, and infection has been widely investigated. ${ }^{18-21}$ Nanoscale features on the implant surface offer increased cell adhesion and protein adsorption due to changes in surface energy. ${ }^{22,23}$ The interaction of microscale cells with their environment occurs through a number of nanotopographical and biochemical

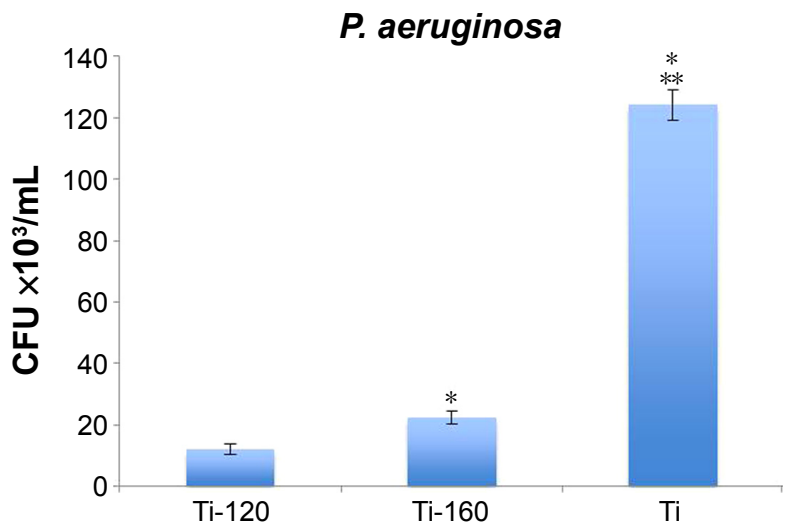

Figure $3 P$. aeruginosa colony-forming units per milliliter on plain titanium and treated titanium.

Notes: Data are expressed as the mean \pm standard error of the mean; $N=3$; $* P<0.01$ compared with $\mathrm{Ti}-\mathrm{I} 20$ and $* * P<0.0 \mathrm{I}$ compared with $\mathrm{Ti}-\mathrm{I} 20$ and $\mathrm{Ti}-\mathrm{I} 60$.

Abbreviation: $P$. aeruginosa, Pseudomonas aeruginosa. 


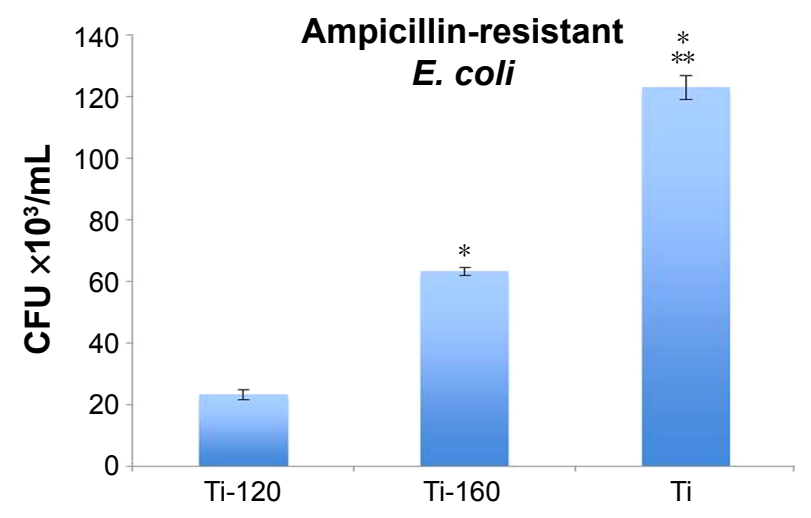

Figure 4 Ampicillin-resistant $E$. coli colony-forming units per milliliter on plain titanium and treated titanium.

Notes: Data are expressed as the mean \pm standard error of the mean; $N=3$ $* P<0.01$ compared with $\mathrm{Ti}-\mathrm{I} 20$ and $* * P<0.01$ compared with $\mathrm{Ti}-\mathrm{I} 20$ and $\mathrm{Ti}-160$ Abbreviation: E. coli, Escherichia coli.

cues. Thus, material surfaces with biochemical ${ }^{24-27}$ or topographical ${ }^{28-30}$ modifications similar to that of the natural in vivo environment have been shown to elicit cell-specific functionality, enabled through biomimetic cues. Peptidemodified $^{31,32}$ and growth factor-functionalized ${ }^{33,34}$ surfaces have shown increased cellular function. Various biomaterial surfaces such as nanoparticles, nanofibers, ${ }^{35,36}$ nanopores, nanowires, nanostructured hydrogels, and nanotube arrays have been fabricated and extensively studied. The goal of these nanostructures is to provide nanoscale cues for a variety of cell types. ${ }^{37}$ Different approaches are being used in an effort to obtain the desired bone-implant interface. The ideal implant should present a surface conducive to or that will induce osseointegration, regardless of implantation site, bone quantity, bone quality, etc. As Kasemo and Lausmaa, ${ }^{38}$ among others, have described, biological tissues interact mainly with the outermost atomic layers of an implant. Although secondary and other by-product reactions will occur, the "primary interaction zone" is generally $\sim 0.1-1 \mathrm{~nm}$. Consequently, much effort is being devoted to methods of modifying surfaces of existing biomaterials to achieve desirable biological responses.

The emergent antimicrobial properties of nanotextured surfaces reduce bacterial adhesion and proliferation. Materials such as $\mathrm{ZnO}, \mathrm{TiO}_{2}$, polymers, and carbon nanotubes have been good examples of this. $\mathrm{TiO}_{2}$ is a naturally occurring oxide formed on titanium surfaces. ${ }^{38}$ Nanotechnology serves as a promising tool in tissue engineering as it allows us to generate surfaces that mimic the constituent properties of natural tissues. By altering the surface energy of implants, one can subsequently change protein adsorption, alter protein bioactivity, and promote cell function while at the same time reducing bacterial adhesion and proliferation. This is now a popular concept in the industry, and nanoparticles are being
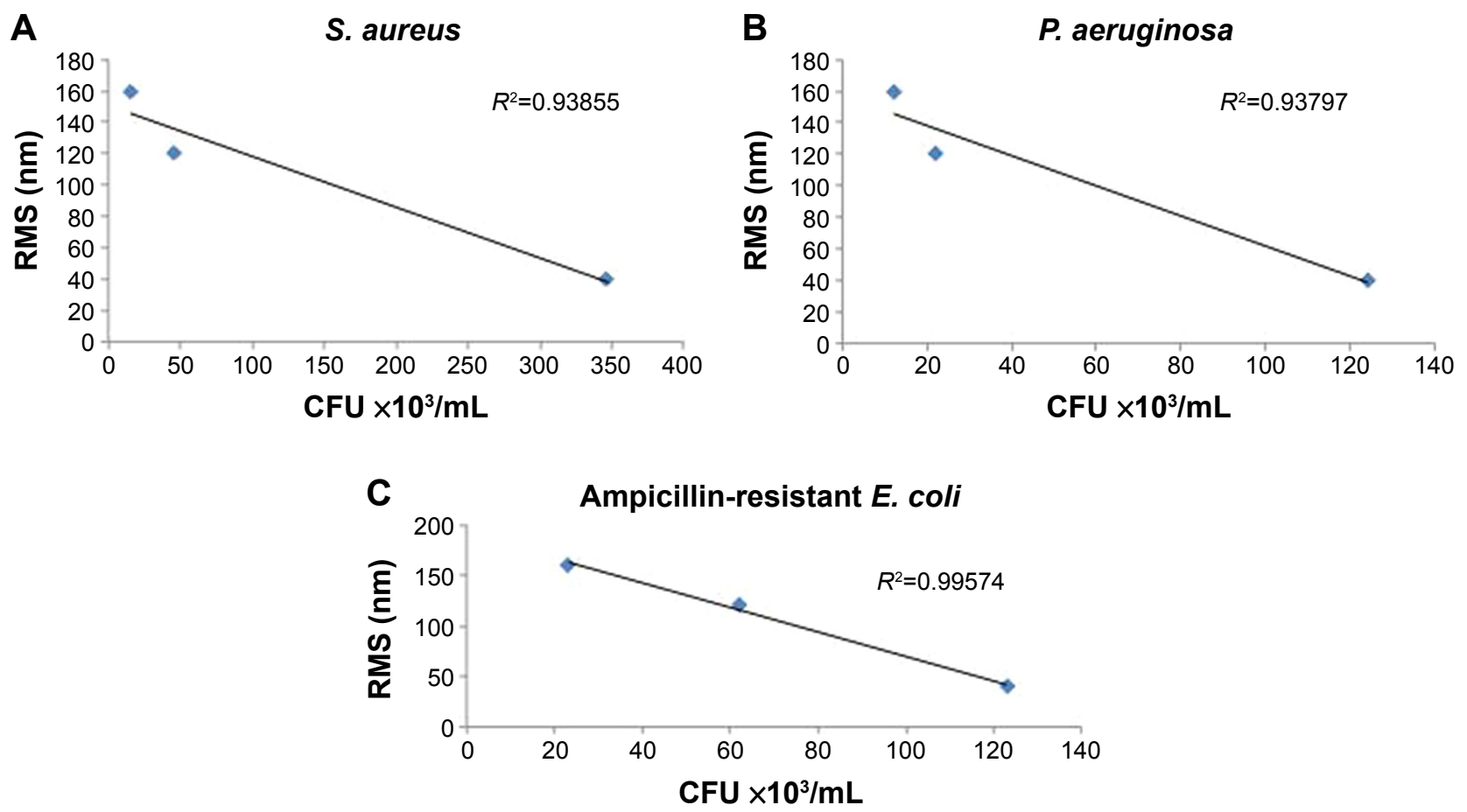

Figure 5 The root-mean-square (RMS) roughness (as obtained by AFM) of the surface-treated samples plotted against the number of bacterial colonies for all three strains of bacteria; (A) S. aureus, (B) P. aeruginosa and (C) Ampicillin resistant $E$. coli after 16 hours of culture.

Abbreviations: AFM, atomic force microscopy; P. aeruginosa, Pseudomonas aeruginosa; S. aureus, Staphylococcus aureus; E. coli, Escherichia coli. 


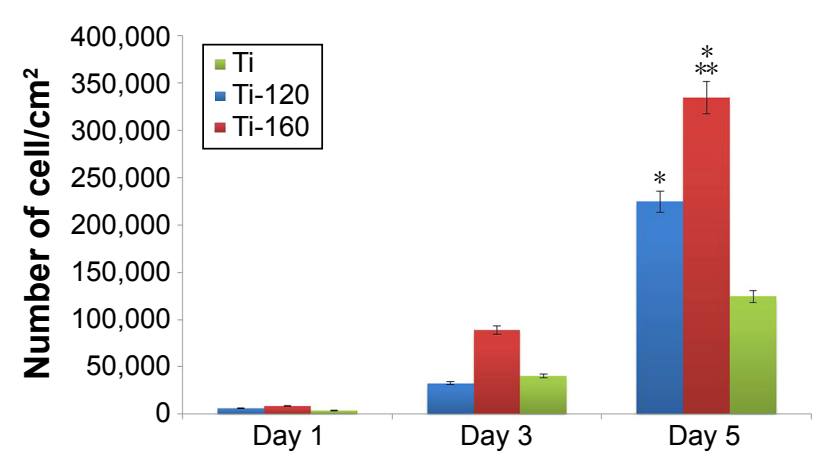

Figure 6 Osteoblast adhesion and proliferation on $\mathrm{Ti}-\mathrm{I} 20$, Ti- 60 , and untreated titanium surfaces.

Notes: Data are expressed as the mean \pm standard error of the mean. $* P<0.01$ compared with Ti-I20 on days I and 3 and $* * P<0.01$ compared with Ti-I20 and Ti-I60 on days I and 3.

incorporated into paints, dyes, etc. Nanoparticles disrupt the bacterial cell membrane by penetrating it or causing free radical formation. Lysosomal fusion in mammalian cells causes the disruption of these free radicals and reduces the damage caused by free radicals. This allows researchers to selectively target bacterial cells while maintaining healthy cell function. Finally, while it is anticipated that these surfaces will reduce immediate bacterial colonization and at the same time promote osteoblast functions, thus providing an immediate positive interaction in the body, it is unclear over what sustained time period such properties will last; this will require further investigation.

\section{Conclusion}

Biofilm formation and bacterial infection of implants is a complex issue in which many variables are involved. Bacteria that are present throughout the body can be treated by the host immune system and traditional antibiotic treatment. However, once the bacteria have colonized and form a biofilm, the course of treatment becomes more challenging since biofilms are not very responsive to traditional treatments. S. aureus is the most common bacteria present in clinical infections and biofilms on medical devices, ${ }^{38}$ where preventing the adhesion and colonization of bacteria can be a tremendous benefit to reduce infections and to facilitate the treatment of free-floating planktonic bacteria not adherent to implant surfaces. Technology that can create nanoscale surface roughness, similar to that presented here, can reduce bacterial colonization and, thus, may have a synergistic effect in treating infections. These promising results show that just by changing the surface topography of the implant surface by creating Ti-120 and Ti-160 nanotextured $\mathrm{TiO}_{2}$ surfaces, one can significantly reduce bacterial adhesion and growth for both gram-positive and gram-negative bacteria. A reduction in bacteria adhesion and growth was also observed for an antibiotic-resistant bacterium, as well as inducing upregulation of osteoblast activity for Ti-160. Finally, moving forward from these results, with the aid of a biological, mechanical, and mechanistic understanding of the coatings, optimal coatings can be developed that offer improved osteoblast adhesion and proliferation, while reducing bacterial colonization, all without the use of the antibiotics.

\section{Acknowledgments}

The authors would like to thank Northeastern University and Tyber Medical LLC for equipment and funding. Tyber Medical LLC is commercializing this material, and there is a financial interest in the results of the present research.

\section{Disclosure}

The authors report no conflicts of interest in this work.

\section{References}

1. Costerton B. Microbial ecology comes of age and joins the general ecology community. Proc Natl Acad Sci U S A. 2004;101:16983-16984.

2. Bazaka K, Jacob MV, Chrzanowski W, Ostrikov K. Anti-bacterial surfaces: natural agents, mechanisms of action, and plasma surface modification. RSC Adv. 2015;5:48739-48759.

3. Zhao L, Chu PK, Zhang Y, Wu Z. Antibacterial coatings on titanium implants. J Biomed Mater Res B Appl Biomater. 2009;91B(1): 470-480.

4. Li H, Khor KA, Cheang P. Titanium dioxide reinforced hydroxyapatite coatings deposited by high velocity oxy-fuel (HVOF) spray. Biomaterials. 2002;23(1):85-91.

5. Ballo AM, Bjöörn D, Åstrand M, Palmquist A, Lausmaa J, Thomsen P. Bone response to physical-vapour-deposited titanium dioxide coatings on titanium implants. Clin Oral Implants Res. 2013;24(9):1009-1017.

6. Alt V, Bitschnau A, Osterling J, et al. The effects of combined gentamicin-hydroxyapatite coating for cementless joint prostheses on the reduction of infection rates in a rabbit infection prophylaxis model. Biomaterials. 2006;27(26):4627-4634.

7. Carter DR, Beaupre GS, Giori NJ, Helms JA. Mechanobiology of skeletal regeneration. Clin Orthop Relat Res. 1998;355:S41-S55.

8. Stigter M, Bezemer J, de Groot K, Layrolle P. Incorporation of different antibiotics into carbonated hydroxyapatite coatings on titanium implants, release and antibiotic efficacy. J Control Release. 2004;99(1): 127-137.

9. Zhang ZT, Dunn MF, Xiao TD, Tomsia AP, Saiz E. Nanostructured hydroxyapatite coatings for improved adhesion and corrosion resistance for medical implants. In: Komarneni S, Parker JC, Vaia RA, Lu GQ, Matsushita JI, editors. Nanophase and Nanocomposite Materials IV. Warrendale: Materials Research Society; 2002:291-296.

10. Radin S, Campbell JT, Ducheyne P, Cuckler JM. Calcium phosphate ceramic coatings as carriers of vancomycin. Biomaterials. 1997;18(11): 777-782.

11. Yamamura K, Iwata H, Yotsuyanagi T. Synthesis of antibiotic-loaded hydroxyapatite beads and in vitro drug release testing. J Biomed Mater Res. 1992;26(8):1053-1064.

12. Hsu LC, Fang J, Borca-Tasciuc DA, Worobo RW, Moraru CI. Effect of micro- and nanoscale topography on the adhesion of bacterial cells to solid surfaces. Appl Environ Microbiol. 2013;79(8):2703-2712.

13. Sullivan MP, McHale KJ, Parvizi J, Mehta S. Nanotechnology: current concepts in orthopaedic surgery and future directions. Bone Joint $J$. 2014;96B(5):569-573. 
14. Puckett SD, Taylor E, Raimondo T, Webster TJ. The relationship between the nanostructure of titanium surfaces and bacterial attachment. Biomaterials. 2010;31(4):706-713.

15. Braem A, Van Mellaert L, Mattheys T, et al. Staphylococcal biofilm growth on smooth and porous titanium coatings for biomedical applications. J Biomed Mater Res A. 2014;102(1):215-224.

16. Besra L, Liu M. A review on fundamentals and applications of electrophoretic deposition (EPD). Prog Mater Sci. 2007;52:1-61.

17. Sato M, Slamovich EB, Webster TJ. Enhanced osteoblast adhesion on hydrothermally treated hydroxyapatite/titania/poly(lactide-co-glycolide) sol-gel titanium coatings. Biomaterials. 2005;26(12):1349-1357.

18. Curtis ASG, Gadegaard N, Dalby MJ, Riehle MO, Wilkinson CDW, Aitchison G. Cells react to nanoscale order and symmetry in their surroundings. IEEE Trans Nanobioscience. 2004;3(1):61-65.

19. Decuzzi P, Ferrari M. Modulating cellular adhesion through nanotopography. Biomaterials. 2010;31(1):173-179.

20. Khang D, Carpenter J, Chun YW, Pareta R, Webster TJ. Nanotechnology for regenerative medicine. Biomed Microdevices. 2010;12(4): 575-587.

21. Valiev RZ, Semenova IP, Latysh VV, et al. Nanostructured titanium for biomedical applications. Adv Eng Mater. 2008;10:B15-B17.

22. Smith BS, Yoriya S, Grissom L, Grimes CA, Popat KC. Hemocompatibility of titania nanotube arrays. J Biomed Mater Res A. 2011;96A:608. [J Biomed Mater Res A. 2010;95A:350].

23. Lord MS, Foss M, Besenbacher F. Influence of nanoscale surface topography on protein adsorption and cellular response. Nano Today. 2010;5:66-78.

24. Morra M. Biochemical modification of titanium surfaces: peptides and ECM proteins. Eur Cell Mater. 2006;12:1-15.

25. Dee KC, Andersen TT, Bizios R. Design and function of novel osteoblast-adhesive peptides for chemical modification of biomaterials. J Biomed Mater Res. 1998;40(3):371-377.

26. Vogel V, Sheetz MP. Cell fate regulation by coupling mechanical cycles to biochemical signaling pathways. Curr Opin Cell Biol. 2009;21(1): 38-46.

27. Dadsetan M, Jones JA, Hiltner A, Anderson JM. Surface chemistry mediates adhesive structure, cytoskeletal organization, and fusion of macrophages. J Biomed Mater Res A. 2004;71A(3):439-448.
28. Puckett SD, Lee PP, Ciombor DM, Aaron RK, Webster TJ. Nanotextured titanium surfaces for enhancing skin growth on transcutaneous osseointegrated devices. Acta Biomater. 2010;6(6):2352-2362.

29. Apicella A, Aversa R. A biomimetic and biomechanical approach for tissue engineering hybrid nanomaterials and a piezoelectric tunable bending apparatus for mechanically stimulated osteoblast cells growth. Biodevices: Proceedings of the International Conference on Biomedical Electronics and Devices, Vilamoura, Algarve, Portugal; 1-4 February, 2012. Scitepress Digital Library; 2012:280-285.

30. Biggs MJP, Richards RG, Dalby MJ. Nanotopographical modification: a regulator of cellular function through focal adhesions. Nanomedicine. 2010;6(5):619-633.

31. Werner S, Huck O, Frisch B, et al. The effect of microstructured surfaces and laminin-derived peptide coatings on soft tissue interactions with titanium dental implants. Biomaterials. 2009;30(12):2291-2301.

32. Grafahrend D, Heffels K-H, Moeller M, Klee D, Groll J. Electrospun, biofunctionalized fibers as tailored in vitro substrates for keratinocyte cell culture. Macromol Biosci. 2010;10(9):1022-1027.

33. Clark RAF. Growth-factors and wound repair. J Cell Biochem. 1991; 46:1-2.

34. Gailit J, Clarke C, Newman D, Tonnesen MG, Mosesson MW, Clark RAF. Human fibroblasts bind directly to fibrinogen at RGD sites through integrin alpha(v)beta 3. Exp Cell Res. 1997;232:118-126.

35. Khang D, Sato M, Price RL, Ribbe AE, Webster TJ. Selective adhesion and mineral deposition by osteoblasts on carbon nanofiber patterns. Int J Nanomedicine. 2006;1(1):65-72.

36. La Flamme KE, Popat KC, Leoni L, et al. Biocompatibility of nanoporous alumina membranes for immunoisolation. Biomaterials. 2007; 28(16):2638-2645.

37. Bauer S, Park J, Faltenbacher J, Berger S, von der Mark K, Schmuki P. Size selective behavior of mesenchymal stem cells on $\mathrm{ZrO}(2)$ and $\mathrm{TiO}(2)$ nanotube arrays. Integr Biol (Camb). 2009;1:525-532.

38. Kasemo B, Lausmaa J. Surface science aspects on inorganic biomaterials. CRC Crit Rev Biocompat. 1986;2:335-380.
International Journal of Nanomedicine

\section{Publish your work in this journal}

The International Journal of Nanomedicine is an international, peerreviewed journal focusing on the application of nanotechnology in diagnostics, therapeutics, and drug delivery systems throughout the biomedical field. This journal is indexed on PubMed Central, MedLine, CAS, SciSearch $®$, Current Contents $\AA /$ Clinical Medicine,

\section{Dovepress}

Journal Citation Reports/Science Edition, EMBase, Scopus and the Elsevier Bibliographic databases. The manuscript management system is completely online and includes a very quick and fair peer-review system, which is all easy to use. Visit http://www.dovepress.com/ testimonials.php to read real quotes from published authors. 